\title{
The effect of training and supervision on primary health care workers' competence to deliver maternal depression inclusive health education in Ibadan, Nigeria: a quasi-experimental study.
}

\section{Adeyinka Olufolake Adefolarin ( $\nabla$ aadefolarin@cartafrica.org )}

Imperial College London Faculty of Medicine https://orcid.org/0000-0001-7238-2413

\section{Gershim Asiki}

African Population and Health Research Center

Oyedunni S Arulogun

Centre for Entrepreneurship and Innovation, University of Ibadan

Oye Gureje

WHO Collaborating Centre for Research and Training in Mental Health and Neuroscience and Drug abuse, Department of Psychiatry, University of Ibadan

\section{Research article}

Keywords: maternal depression, primary health care workers

Posted Date: August 24th, 2020

DOI: https://doi.org/10.21203/rs.3.rs-35172/v1

License: (9) This work is licensed under a Creative Commons Attribution 4.0 International License. Read Full License

Version of Record: A version of this preprint was published at BMC Health Services Research on November 30th, 2021. See the published version at https://doi.org/10.1186/s12913-021-07208-3. 


\section{Abstract}

Background Health workers lacked the competence to address maternal depression in routine the health education in Nigeria. Hence, awareness among maternal-child health clients is low. We assessed the effect of training and/ supervision on knowledge, skills and self-efficacy of primary healthcare workers in delivering health talks and the clients' knowledge on maternal depression.

Methods A quasi-experimental study design was adopted. Five Local Government Area (LGAs) in the Ibadan metropolis were grouped according to geographical proximity and randomly assigned to experimental (Group $A=$ two LGAs) and control (Group B= three LGAs) with 12 primary health centres in each group. All primary health care workers recruited in group A received a one-day training on maternal depression. Good Knowledge Gain (GKG), Good Skill Gain (GSG) and Self-Efficacy (SEG) based on bloom's cut off were assessed in both groups. After 1 week, the knowledge of all the PHCs' attendees in the two groups were assessed. A week after, a half of group A's PHCs received supportive supervision and a clinic based health education skill assessment was conducted. The knowledge of clients and their health seeking were also assessed. Fisher's exact test, independent $t$ test and Poisson regression were used to analyze differences in percentages and mean/ factors associated with GKG, GSG and SE, using SPSS 25.

Results Training improved gains in the experimental versus controls as follows: GKG (84.3\% vs. $15.7 \%)$, GSG $(90.7 \%$ vs $9.3 \%)$ and SEG (100\% vs $0 \%)$. Training contributed to the good gain in knowledge $(R R=6.03 ; 95 \% C l=2.44-16.46 ; p<0.01)$; skill $(R R=1.88 ; C l=1.53-2.33 ; p<0.01)$.) and self-efficacy $(R R=2.74 ;$ $\mathrm{Cl}=2.07-2.73 ; \mathrm{p}<0.01)$. Clients in the experimental group had higher knowledge gain score than in the control ( $7.10 \pm 2.4$ versus $-0.45 \pm 2.37$ ); $p<0.01)$. The rater supervisor observed better motivation in the supervised group than the not supervised. Forty clients sought help in the intervention group while none in the control group. Thirty-five clients sought help in the supervised group while only five did in the not supervised.

Conclusions Training followed by supervision improved the competence of health workers to transfer knowledge to clients. This is recommended in the primary healthcare settings to improve uptake of maternal mental health services.

\section{Background}

Maternal depression is a public health problem of global concern (1), disproportionately affecting the low and middle income countries (LMICs)(2). There is a higher prevalence of maternal depression in LMICs reporting up to $65 \%$ in some settings compared to $17 \%$ reported in the high income countries. The burden in the LMICs raises concerns as depression is reported as the second leading cause of disability and is projected to be the leading cause of suicide by 2030(3). This fact will possibly enlist depression as the most detrimental illness among all mental disorders and non-communicable diseases. Available literature 
already shows that effects of depression are worse during pregnancy or after childbirth. It leads to poor quality of life for the woman, poor birth outcomes and poor child developmental outcomes(4).

In the LMICs including Nigeria, maternal depression is referred to as "a hidden burden" (1), because it is underdiagnosed, under-treated and there is lack of population awareness about the condition. There was an initial view that maternal depression did not exist in Africa because of strong family social support systems that are protective (5);(6). However, this no longer stands as migration is breaking down the family support system and there is no structured social support in place (7). Also, more evidence of high prevalence is emerging from studies which have used culturally adaptable tools (1). Therefore, available evidence shows that the prevalence of maternal depression in Africa is high and the consequences are equally bad (8). However, awareness at the population level is still low (9). There is a need for primary health care workers to offer health education on mental health to women during clinic attendance of maternal and child health services. However, the pre-service training on mental health issues at undergraduate and graduate level is not adequate(10).

In Nigeria, health education is a routine service provision at the primary health care level but mental health is rarely addressed. The reason adduced to this was that primary health care workers did not have the competence to provide culturally appropriate maternal depression inclusive health education(11). However, with the increasing decentralization of mental health service to primary health clinics, there is an established need to build the capacity of non-specialist primary healthcare workers to provide mental health service through training and supervision (12).

In this study we utilized training and supervision and hypothesized that this would improve knowledge, skill and self-efficacy of primary health care workers in maternal depression education delivery. We also evaluated how their performance influenced clients' knowledge.

\section{Methods}

\section{Study design and study setting}

A two-group prestest-posttest quasi experimental study was conducted from October to December 2016 in Ibadan, Oyo state. The federal system of government in Nigeria functions at three tiers: national, state and local governments. The Local Government Area (LGA) is primarily responsible for routine primary health care services. The primary healthcare care centres (PHC) are the first level of contact with the community (13). Ibadan is in the South Western part of Nigeria where the indegenes are the Yoruba speaking tribe who are predomonantly farmers, petty traders and artisans. The total land area of Ibadan is $3,123 \mathrm{~km} 2,15.0 \%$ of which is urban and the rest classified as peri-urban. It has 11 LGA (pronvices). This study took place in 5 LGAs in the metropolis. The other 6 LGAs from periurban and rural areas were excluded. The population distribition in the 5 LGAs selected for the study are Ibadan North (IBN-306,795), Ibadan North West (IBNW-152,843). Ibadan South East (IBSE- 266,046). Ibadan South West (IBSW282,585) and Ibadan North East (IBNE-330,399). 
This study took place at the comprehensive health centres known as primary health centres (PHCs) in the ward system. A ward is the smallest political structure, consisting of a geographical area with a population range of 10,000 to 30,000 people served by at least one PHC. There are approximately 10 wards in one LGA. The LGA has a department of health which coordinates the administration of the primary health care. At the time of this study only one doctor was in charge of coordinating all the primary health care in each LGA. At the PHC level, laboratory testing, pharmacy, minor surgery 24 hours service, maternal-child health service (antenatal, delivery and immunization), general health care, community outreaches, admission and referral services are delivered by nurses and midwives as well as some cadres of community health workers. Below the PHC level are two levels: primary health clinics only offering maternal child-health care, treatment of malaria and other common diseases to a set of villages with a population of 2000-5000 people, and health posts providing only community outreach, maternal child health service, the dispensing of medication serving approximately 500 people (14)

\section{Selection of intervention LGAs and PHCs}

The intervention took place in two of the 5 LGAs in the metropolis (Figure 1). In order to select a group of LGAs for the intervention, the LGAs were first grouped according to geographical proximity and number of PHCs. Two adjacent LGAs: IBN and IBNW which had 12 PHCs were combined together as group A and three LGAs IBSW, IBSE and IBNE also with 12 PHCs were grouped together as B.

These two groups were then allocated randomly into experimental group (A) and control group (B) through a public lottery. In brief, the two groups were labeled on a piece of paper as group $A$ and $B$, rolled into large balls placed inside a concealed box. It was agreed that the first ball to be picked would be considered the experimental group and the one remaining in the box would be the control. After shaking the box, a community leader who knew nothing about the study was called to pick one ball from the box.

\section{Intervention}

The intervention used the apprentice model (15), which combines training and supervision in a sequential order. The concept consists of selection of trainees with specific qualifications, classroom teaching, and real world implementation of learned subject, supportive supervision and evaluation. The objective of the training was to build the competence of primary health workers to deliver culturally appropriate health talk on maternal depression(11). We developed a training guide which has the details of the training program activities (the objective, focus of each topic, method, materials and evaluation). The method of delivering the training included lecture, role play, brainstorming and return demonstration (supplementary table 1). A supervision guide developed by WHO was used(16),(17). The validated health education aid provided for the trainees (primary health care workers) included poster, song, leaflet (avaialable in Yoruba, Ehglish and Pigin english languages) and sample of maternal depression health talk (health talk guide). They were developed by researchers A.O and O.S and the training was facilitated by them. The content of the training addresses perceived susceptibility and perceived consequences of maternal child- health clients to maternal depression based on the concept of health belief model (18). The health workers were trained to deliver explicit health education (health talk) on maternal depression in Yoruba language. 


\section{Training}

The training was a one-day training of PHC workers in a classroom with each session for minimum 20 minutes (supplementary table 2). It mainly focused on teaching health workers on culturally acceptable terms for maternal depression and addressing myth and misconception around maternal depression (based on feedback form preliminary study in the community (9), risk factors, signs, consequences, prevention, help seeking and misconception about maternal depression (supplementary table 2). Training participants were trained in culturally appropriate health talk delivery on maternal depression. After training, all the trained participants were rostered by their coordinators to provide maternal depression inclusive health education in their various PHCs. The control group did not receive any training but they provided health education as standard practice.

\section{Supervision}

Two weeks after training, half of the experimental PHCs were randomly selected for supervision. The supervision lasted for one-month. The supervisor encouraged mutual communication both online and offline with the trainees (primary health care workers) and ensured strict adherence to the health talk guide for uniformity. The supervisor supported the trainees on four visits each in all the 6 supervised clinics (group/arm). The researchers monitored the activities of a trained supervisor.

\section{Study participants, sample size}

In order to evaluate the intervention effect, immediate pre-post evaluation of primary healthcare workers' knowledge, skills and self-efficacy assessments were conducted as a primary outcome. Additionally, skills of the primary health workers were assessed after supervision. One-week post-training, a one-time evaluation of knowledge of clients was done pre and post clinic based health education in both groups. At the end, one-time knowledge assessment was carried out among the clients in each group.

The primary participants were the PHC health workers in the 5 LGAs who provide group health education These included the chief nursing officer, community health officer and community extension worker distributed in the LGAs as follows: IBN (6 PHCs, 72 staff), IBNE (6 PHCs, 53 staff), IBNW (4 PHCs, 45 staff), IBSW (4 PHC, 35 staff) and IBSE ( 4 PHCs: 55staff). However health workers who had less than 10 years to retirement and those who were on leave were excluded. The clients attending maternal-and child health clinics (both antenatal and immunization clinics) were considered the ultimate beneficiaries.

We used the sample size formula for comparing two proportions (19) to estimate the sample size for health workers who participated in the classroom training intervention.

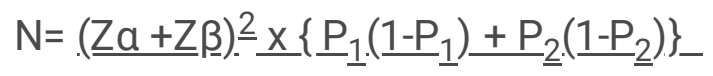

$$
\left(P_{1}-P_{2}\right)^{2}
$$


We assumed that $\mathrm{P}_{1}, 50 \%$ proportion in the control group will score above average since no previous local studies were available. The $P_{2}$ was assumed to be $75 \%$, the proportion of respondents with good knowledge, (score above average). The effect size which is the difference $P_{1}$ and $P_{2}$ was assumed to be $25 \%$. The constant $Z a^{2}=1.96, Z \beta^{2}=0.84$. The calculated $N$ is $54.91 \approx 55$ for each group. Adjusting for $10 \%$ non-response gives a sample size of 60.5 . Each group had 60 participants per study arm. The calculated sample size 60 was distributed into the 2 LGAs in the experimental group while 60 distributed in the 3 LGAs in control proportionate to the total number of health care workers in each PHC.

A convenient sample size of $50 \%$ of clients were selected for knowledge assessment before and after training of primary healthcare workers and was repeated in the supervised and un-supervised clinics.

\section{Procedure of data collection}

Four Research Assistants (RAs); $\mathrm{Y}$ and $\mathrm{Z}$ with higher diploma degree and research field work experience were recruited. Another two RAs ( $Q$ and $X)$ had degree in nursing and they were assigned the role of supervision ( $Q$ supportive supervision and $X$ rater supervisor), and $R A s(Y, Z)$ were assigned the role of assisting questionnaire administration among the maternal-child health clinic attendees. The RAs were also trained to assist with the training logistics while AO and OS delivered training to the health workers (Supplementary table 2). Codes were assigned to all trainees in order to track their pre and post knowledge, skill and self-efficacy assessments. Trainees responded to self-administered questionnaire of knowledge and self-efficacy while each of them demonstrated health talk and their skill was assessed by researchers A.O and O.S. Figure 1 shows one-week post- training intervention, two RAs ( $Y$ and $Z$ ) did a one-time assessment of knowledge of the maternal-child health clinic attendees (clients) in experimental (12clinics) and controls (12clinics) before and health education session. Figure 1 also shows the data collection of supervision intervention. Two weeks after training; $Y$ and $Z$ did an assessment of the clients who attended the experimental clinics which were group into supervised and not-supervised alone. RA $(X)$ made a $1^{\text {st }}$ visit to the 12 clinics and she made the initial assessment of the clinic based skill of delivery of maternal depression inclusive health talk before supervision started. After this, RA (Q) started providing supportive supervision to only 6 clinics and documented her observation on site note during the four visits. Each visit lasted for minimum of 45 mins during the different clinic days of each PHC. After the $4^{\text {th }}$ visit of RA (Q), RA X made second visit to assess the clinic based skill of delivery of maternal depression inclusive health talk after supervision ended. RA $(Y, Z)$ also made the $2^{\text {nd }}$ visit to the 12 clinics; $(6$ supervised and 6 not-supervised) to assess the clinic attendees' knowledge after supportive supervision was provided to the supervised group.

\section{Instrument for data collection and measurements}

Study instruments for health workers included a self-administered 10 scores- item questionaire adapted from multichoice questionaire on depression knowledge (20), 15 scores -observational skill checklist and a self administered 20 point self efficacy likert scale questionaires adapted from the teacher self-efficacy questionnaire (21). The questionnaires also contain a section on sociodemographic characteristics. The 
same 15 scores- observational skill checklist was used for the supervsion following training. 15 scoresknowledge questionannaire was used among clients. A record check was used for clients' health seeking for depressive symptoms. All questionnaires were developed and pretested before use specifically for this study and they are available as additional files.

\section{Data analysis}

The primary outcomes for the training intervention were the propotion of health workers with a good gains in knowledge, skill and self-efficacy respectively. The pre-training scores were subtracted from the post-training scores to compute the gain and $50 \%$ or more gain was considered a good gain by Bloom's cut-off (22). The socio demographic data of the health worker trainees was analysed using cross tabulation , frequencies and fisher exact test to compare the characteristics of experimental and control participants. While the sociodemographic charateristics of the maternal child-health clients were analyzed as count and frequency. Since the proportion of participants with good gain was high, we could not use logistic regression to compute odds ratio as this would exaggerate the associations as shown before (23). We used poisson regression to compute prevalence rate ratios to ascertain the effect of training on the outcome variables while controlling for other variables as adjusted relative risk on univariate analysis and as unadjusted on multivariate (24). Variables on Good knowledge, skill and selfefficacy were first analyzed with fisher's exact and only the variables with a statistical significance $<0.01$ were analyzed one after the other (adjusted) with poissson test . Further test was done on all the variables pooled together at once(unadjusted) using the same poisson test as multivariate.

Our secondary outcomes were the clients' knowledge pre and post training and supervision respectively. The difference of the mean score for these scores was obtained by independent $t$ test since it was a group mean among different clients assessed before and after health education; after training and after supervision. Also, across the supervised and not-supervised PHCs. We used SPSS 25 for the analysis. All levels of significance were set at 0.01 at $95 \%$ confidence interval.

\section{Ethical consideration}

Ethical approval was obtained from the Oyo state ethical review board, ref no AD 13/479/2016. Letter of permission was also obtained from the PHC coordinators of the 5 selected LGAs. Written informed consents were obtained from health workers, identity was protected and confidentiality ensured. Study consents were also taken from clients, as they were given the opportunity to withdraw their consent and decline participation even after enrolment.

\section{Results}

\section{Participants' recruitment profile}

Five LGAs were selected for the study after excluding 6 for their location in peri-urban or rural areas. Out of the 60 participants planned to be recruited from 12 primary health clinics per study arm 50 and 47 
health workers participated respectively for experimental and control arms. The main reason for nonresponse was engagement in national immunization campaign that took place around the period of recruitment. To assess the effect of training of health workers on clients' knowledge, 120 clients in the experimental arm and 117 from control arm completed the pre and post-test. For the assessment of supervision intervention 97 clients were assessed in supervised arm (Figure 2).

\section{Socio-demographic characteristics of health workers and clients who were assessed during the study}

As shown in table 1 the mean age of the health workers in the two arms was similar (mean age $45.4 \pm 5.9$ years in experimental arm, versus $46 \pm 6.1$ years for the control arm) and all were Yorubas Most of the health workers had education up to higher national diploma (HND) level in both arms. The characteristics that differed between experimental and control arm participants respectively were: less proportion of senior nursing staff ( $24.0 \%$ versus $72.3 \%)$, more staff with more than 10 years of experience ( $88 \%$ versus $0 \%$ ), fewer participants with previous training in maternal depression (34.0\% versus $59.6 \%$ ) and more participants involved in health talk delivery control (42\% versus $21.3 \%$ ).

The characteristics of the clients assessed after the training intervention were similar in both arms. In brief, the mean age of clients in the experimental and control groups were $29.0 \pm 5.6$ and $29.3 \pm 5.7$ years respectively, all were of reproductive age with more than three quarters in the age bracket of 19-30 years, half were pregnant, and the other half were nursing mothers, more than $80 \%$ had schooling beyond primary and junior school and less than $10 \%$ were unemployed (supplementary table 3 ). Similarly, the clients assessed for effect of supervision form half of the PHCs in the experimental arm have similar characteristics when we compared those in the PHCs where supervision was offered and those not offered (supplementary table 4).

Table 1: Comparison of socio demographic characteristics of primary health workers across the experimental group and control group. 


\begin{tabular}{|c|c|c|c|}
\hline Sociodemographic characteristics & $\begin{array}{l}\text { Experimental arm } \\
\mathrm{N}=50\end{array}$ & $\begin{array}{l}\text { Control arm } \\
\mathrm{N}=47\end{array}$ & $\begin{array}{l}\text { Fisher } \\
\text { exact } \\
\text { p value }\end{array}$ \\
\hline \multicolumn{4}{|l|}{ Age (years) } \\
\hline$<45$ & $26(52 \%)$ & $27(57.4 \%)$ & 0.37 \\
\hline \multirow[t]{2}{*}{$>45$} & $24(48 \%)$ & $20(42.6 \%)$ & \\
\hline & $50(100 \%)$ & $47(100 \%)$ & \\
\hline \multicolumn{4}{|l|}{ Education } \\
\hline$<\mathrm{HND}^{1}$ & $22(44.0 \%)$ & $13(27.7 \%)$ & 0.14 \\
\hline \multirow[t]{2}{*}{$>$ HND } & $28(56.0 \%)$ & $34(72.3 \%)$ & \\
\hline & $50(100 \%)$ & $47(100 \%)$ & \\
\hline \multicolumn{4}{|l|}{ Designation } \\
\hline $\mathrm{CNO}^{2} / \mathrm{PNO}^{3} / \mathrm{CHO}^{4}$ & $24(48.0 \%)$ & $34(72.3 \%)$ & 0.02 \\
\hline \multirow[t]{2}{*}{$\mathrm{CHEW}^{5}$} & $26(52.0 \%)$ & $13(27.7 \%)$ & \\
\hline & $50(100 \%)$ & $47(100 \%)$ & \\
\hline \multicolumn{4}{|l|}{ Years of experience } \\
\hline$<10$ years & $06(2.0 \%)$ & $47(100 \%)$ & $<0.01$ \\
\hline \multirow[t]{2}{*}{$\geq 10$ years } & $44(88.0 \%)$ & 0 & \\
\hline & $50(100 \%)$ & $47(100 \%)$ & \\
\hline \multicolumn{4}{|c|}{$\begin{array}{l}\text { Previously trained in maternal depression screening and } \\
\text { counseling }\end{array}$} \\
\hline Yes & $12(24.0 \%)$ & $28(59.6 \%)$ & $<0.01$ \\
\hline \multirow[t]{2}{*}{ No } & $38(76.0 \%)$ & $19(40.4 \%)$ & \\
\hline & $50(100 \%)$ & $47(100 \%)$ & \\
\hline \multicolumn{4}{|l|}{ Involves in Health talk } \\
\hline Yes & $21(42.0 \%)$ & $10(21.3 \%)$ & 0.03 \\
\hline \multirow[t]{2}{*}{ No } & $29(58.0 \%)$ & $37(56.1 \%)$ & \\
\hline & $50(100 \%)$ & $47(100 \%)$ & \\
\hline
\end{tabular}

Level of significance $\mathrm{p}<0.05$. $\mathrm{HND}^{1}$ (Higher National Diploma) $\mathrm{CNO}^{2}$ (Chief Nursing Officers), $\mathrm{PNO}^{3}$ (Principal Nursing Officer), $\mathrm{CHO}^{4}$ (Community Health Officers), $\mathrm{CHEW}^{5}$ (Community Health Extension worker)

Comparison of good gain in knowledge, skills and self-efficacy between health workers in the experimental and control arms.

Figure 3 shows a comparison of proportion of health workers with good knowledge (GKG) good skill gain (GSK) and self-efficacy gain (SEG) assessed in the experimental and control groups; : GKG (84.3\% vs. 
$15.7 \%)$, GSG ( $90.7 \%$ vs $9.3 \%)$ and SEG (100\% vs $0 \%)$ respectively. There was a higher proportion of Primary health workers (PHWs) in the experimental group who had good gain in all three outcomes.

\section{Association of good gain in knowledge, skill and self-efficacy with characteristics of the health workers}

Table 2 shows how the sociodemographic characteristics of the health workers were associated with the good gain in knowledge, skill and self-efficacy only. Three factors show statistically significant association with the good gains. These include: being in the experimental arm, previous exposure to training on maternal depression and working experience. Designation of staff had borderline statistical significance with knowledge and skill gain $(p<0.01)$.

Table 2 Factors associated with good gain in knowledge, skill and self-efficacy of trained primary health care workers 


\begin{tabular}{|c|c|c|c|c|c|c|}
\hline ciodemographic characteristics & $\begin{array}{l}\text { Good gain in } \\
\text { Knowledge } \\
\mathrm{N}=97\end{array}$ & $\begin{array}{l}\text { Fisher } \\
\text { exact } \\
\text { p- } \\
\text { value }\end{array}$ & $\begin{array}{l}\text { Good gain } \\
\text { in Skill } \\
\mathrm{N}=97\end{array}$ & $\begin{array}{l}\text { Fisher } \\
\text { exact } \\
\text { p- } \\
\text { value }\end{array}$ & $\begin{array}{l}\text { Good gain in } \\
\text { self-efficacy } \\
\mathrm{N}=97\end{array}$ & $\begin{array}{l}\text { Fisher } \\
\text { exact } \\
\text { p- } \\
\text { value }\end{array}$ \\
\hline ntrol $\mathrm{N}=47$ & $8(15.7 \%)$ & $<0.01$ & $4(9.3 \%)$ & $<0.01$ & 0 & $<0.01$ \\
\hline perimental $\mathrm{N}=50$ & $43(84.3 \%)$ & & 39 (90.7\%) & & $44(100.0 \%)$ & \\
\hline \multicolumn{7}{|l|}{ e (years) } \\
\hline 5 & $26(50.0 \%)$ & 0.54 & $24(55.8 \%)$ & 1.00 & $24(54.5 \%)$ & 1.00 \\
\hline 5 & $25(50.0 \%$ & & $19(44.2 \%)$ & & $20(45.5 \%)$ & \\
\hline \multicolumn{7}{|l|}{ tal } \\
\hline \multicolumn{7}{|l|}{ ucation } \\
\hline IND & $19(37.3 \%)$ & 0.84 & $18(41.9 \%)$ & 0.40 & $19(43.2 \%)$ & 0.21 \\
\hline IND & $32(62.7 \%)$ & & $25(50.1 \%)$ & & $25(56.8 \%)$ & \\
\hline \multicolumn{7}{|l|}{ signation } \\
\hline $\mathrm{JO} / \mathrm{PNO} / \mathrm{CHO}$ & $25(49.0 \%)$ & 0.04 & $20(46.5 \%)$ & $<0.02$ & $22(50.0 \%)$ & 0.97 \\
\hline IEW & $26(51.0 \%)$ & & $23(53.5 \%)$ & & $22(50.0 \%)$ & \\
\hline \multicolumn{7}{|l|}{ perience (years) } \\
\hline 0 & $14(27.5 \%)$ & $<0.01$ & $9(20.9 \%)$ & $<0.01$ & $5(11.4 \%)$ & $<0.01$ \\
\hline 0 & $37(72.5 \%)$ & & $34(79.1 \%)$ & & $39(88.6 \%)$ & \\
\hline \multicolumn{7}{|l|}{$\begin{array}{l}\text { eviously trained in maternal } \\
\text { pression screening and } \\
\text { unseling }\end{array}$} \\
\hline $\mathrm{s}$ & $13(25.5 \%)$ & $<0.01$ & $32(74.4 \%)$ & $<0.01$ & $10(22.7 \%)$ & $<0.01$ \\
\hline 1 & $38(74.5 \%)$ & & $11(25.6 \%)$ & & $34(77.3 \%)$ & \\
\hline \multicolumn{7}{|l|}{ rolve in Health talk } \\
\hline $\mathrm{s}$ & $31(60.8 \%)$ & 0.13 & $26(60.5 \%)$ & 0.19 & $18(40.9 \%)$ & 0.13 \\
\hline \multirow[t]{2}{*}{1} & $20(39.2 \%)$ & & $17(39.5 \%)$ & & $26(59.1 \%)$ & \\
\hline & $51(100.0 \%)$ & & & & & \\
\hline
\end{tabular}




\section{Factors associated with good gain in knowledge, skill and self-efficacy among the Primary health care workers univariate and multivariate analysis}

Table 3 shows results of univariate and multivariate analysis for association between participant characteristics and good gain in knowledge, skill and self-efficacy. In the univariate analysis, being in the experimental group and previous exposure to training were associated with good gain in all the three outcomes (all statistically significant). Those who had worked for 10 years or more were less likely to attain a good gain in knowledge, skills and self-efficacy. Higher cadre staff such as CNO/PNO/ CHO were more likely to attain a good skill gain compared to CHEWs. Age, education level and being involved in a health talk before had no statistically significant associations with all the three outcomes. In multivariate analysis, being in the experimental arm was the only factor that remained statistically significant with the three outcomes with their prevalence rate ratios at 95\% Confidence Intervals (RR [95\% CI]) as follows: GKG (6.03 [2.44-16.46]), GSK (1.88 [1.53-2.33]) and SEG (2.74 [2.07-2.73]).

Table 3. Factors associated with characteristics associated with good gain in knowledge, skill and self-efficacy among primary health care workers at univariate and multivariate analysis 


\begin{tabular}{|c|c|c|c|c|c|c|}
\hline \multirow[t]{3}{*}{ 3ristics } & \multicolumn{2}{|c|}{ Good knowledge gain (GKG) } & \multicolumn{2}{|c|}{ Good Skill gain (GSG) } & \multicolumn{2}{|c|}{$\begin{array}{l}\text { Good Self-Efficacy gain } \\
\text { (SEG) }\end{array}$} \\
\hline & Univariate & Multivariate & Univariate & Multivariate & Univariate & Multivariate \\
\hline & RR (95CI & RR (95\%CI) & $\mathrm{RR}(95 \% \mathrm{CI})$ & $\mathrm{RR}(95 \% \mathrm{CI})$ & $\mathrm{RR}(95 \% \mathrm{CI})$ & $\mathrm{RR}(95 \% \mathrm{CI})$ \\
\hline \multicolumn{7}{|l|}{$\mathrm{m}$} \\
\hline & 1 & 1 & 1 & 1 & 1 & 1 \\
\hline ental & $\begin{array}{l}5.06(2.51- \\
11.60)\end{array}$ & $\begin{array}{l}6.03(2.44- \\
16.46)\end{array}$ & $\begin{array}{l}2.00(1.74- \\
2.31)\end{array}$ & $\begin{array}{l}1.88(1.53- \\
2.33)\end{array}$ & $\begin{array}{l}2.41(2.20- \\
2.65)\end{array}$ & $\begin{array}{l}2.74(2.07- \\
2.73)\end{array}$ \\
\hline rs & 1 & 1 & 1 & 1 & 1 & 1 \\
\hline rs & $\begin{array}{l}0.86(0.50- \\
1.50)\end{array}$ & & $\begin{array}{l}1.02(0.84- \\
1.25)\end{array}$ & & $\begin{array}{l}1.00(0.82- \\
1.22)\end{array}$ & \\
\hline \multicolumn{7}{|l|}{ n } \\
\hline & 1 & 1 & 1 & 1 & 1 & 1 \\
\hline & $\begin{array}{l}1.05(0.59- \\
1.84)\end{array}$ & & $\begin{array}{l}1.12(0.91- \\
1.37)\end{array}$ & & $\begin{array}{l}1.15(0.94- \\
1.41)\end{array}$ & \\
\hline \multicolumn{7}{|l|}{ tion } \\
\hline & 1 & 1 & 1 & 1 & 1 & 1 \\
\hline JO/ CHO & $\begin{array}{l}1.55(0.89- \\
2.69)\end{array}$ & $\begin{array}{l}1.76(0.74- \\
4.57)\end{array}$ & $\begin{array}{l}1.28(1.05- \\
1.56)\end{array}$ & $\begin{array}{l}1.06(0.88- \\
1.27)\end{array}$ & $\begin{array}{l}1.20(0.98- \\
1.47)\end{array}$ & $\begin{array}{l}0.95(0.84- \\
1.07)\end{array}$ \\
\hline nce & 1 & 1 & 1 & 1 & 1 & 1 \\
\hline \multicolumn{7}{|l|}{ rs } \\
\hline rs & $\begin{array}{l}0.47(0.27- \\
0.82)\end{array}$ & $\begin{array}{l}1.81(0.70- \\
5.18)\end{array}$ & $\begin{array}{l}0.58 \quad(0.48- \\
0.69)\end{array}$ & $\begin{array}{l}0.95(0.74- \\
1.23)\end{array}$ & $\begin{array}{l}0.53 \quad(0.44- \\
0.63)\end{array}$ & $\begin{array}{l}0.97(0.82- \\
1.15)\end{array}$ \\
\hline \multicolumn{7}{|l|}{ sly } \\
\hline & 1 & 1 & 1 & 1 & 1 & 1 \\
\hline & $\begin{array}{l}2.05(1.12- \\
4.00)\end{array}$ & $\begin{array}{l}1.30(0.69- \\
2.2 .62)\end{array}$ & $\begin{array}{l}1.33(1.10- \\
1.62)\end{array}$ & $\begin{array}{l}1.05(0.90- \\
1.22)\end{array}$ & $\begin{array}{l}1.41(1.17- \\
1.71)\end{array}$ & $\begin{array}{l}1.03(0.93- \\
1.14)\end{array}$ \\
\hline \multicolumn{7}{|l|}{$\begin{array}{l}\text { L in } \\
\text { alk }\end{array}$} \\
\hline & 1 & & 1 & & 1 & \\
\hline & $\begin{array}{l}1.37(0.77- \\
2.39)\end{array}$ & & $\begin{array}{l}1.17(0.94- \\
1.44)\end{array}$ & & $\begin{array}{l}1.21(0.98- \\
1.49)\end{array}$ & \\
\hline
\end{tabular}
primary health care workers. 
We evaluated the effect of health workers' training on the knowledge of clients accessing maternal-child health PHC services after one week of training health workers. One hundred and twenty clients in experimental PHCs and 117clients in the control PHCs completed pre and post-test. The clients in the experimental group had a mean knowledge score gain of $7.10 \pm 2.4$ while in the control arm, mean knowledge score gain was $-0.45 \pm 2.37 ; t=24.6$; giving a mean difference $=7.55$. $(p<0.01))$. In the experimental group 40 clients sought help for depressive symptoms while none sought help in the control group.

\section{Effect of training followed by supervision on skills of health workers on knowledge of clients on maternal depression}

We first compared the skill level of PHC workers to deliver health education in the two arms (Supervised ad not supervised PHCs). Ninety-seven clients in supervised PHCs and 36 clients in not supervised PHCs completed pre and posttest. We found a statistically significant difference in the mean scores of PHCs supervised and those not supervised $(5.67 \pm 5.4 ; 3.33 \pm 2.4)$ respectively giving a mean difference 2.33; $(p<0.01)$. Rater supervisor observed higher motivation in the supervised PHCs. The clients in the supervised PHCs had mean gained knowledge score $2.75 \pm 2.9$ and those from PHCs not supervised had a score mean gained knowledge score of $1.67 \pm 2.4 ; t=1.984$ giving a mean difference of 1.09. $p=0.06$. Twenty-eight clients sought for help to depressive symptoms in the supervised group while only 5 sought help for depressive symptoms in the not supervised group.

\section{Discussion}

This study utilized one-day training and one-month supportive supervision to ensure improvement in the quality of health talks delivered on maternal depression by primary health workers in the primary health care centres in Ibadan Nigeria. We found that the primary healthcare workers were able to gain good knowledge, skill and self-efficacy after training. Supervision led to significant improvement in clinic based skill to deliver explicit health talk on maternal depression. The knowledge of maternal depression was also transferred successfully to pregnant women and nursing mothers who accessed the health talks in the PHCs. Although, previous training in maternal depression showed an association with gain in knowledge, skills and self-efficacy in the univariate analysis but this association was attenuated at multivariate analysis. This goes to explain that the training offered in this study was likely superior to previous trainings which must have been less specific in content for maternal depression health talk delivery. Possibly, this could also be because mental health training was not adequately taught in health workers' educational institutions (10) (25).

The overall purpose of training and supervision is to ensure competence in delivering culturally appropriate services (12). The evaluation of the immediate outcomes on trained health workers is essentially considered as an evidence that health workers would be able to perform well (26). Indeed, in our study this was the case, the clients gained knowledge on maternal depression and they sought help to their perceived depressive symptoms. The good gain among health workers across the three domains 
of knowledge, skill and self-efficacy outcomes, already indicated good competence to deliver to clients. Mental health issues have diverse health beliefs attached to it across cultures (27)(9), interventions such as ours will go a long way in addressing the knowledge gaps among patients. Training of health workers and empowering them to acquire technical competence to communicate to clients on maternal depression in a way that clients easily understood helped to increase awareness about the condition thus improving uptake of mental health services as shown in our study. In the mental health field, competence to practice is a requirement for non-specialists (12). These findings are consistent with other studies; in South Africa, 7-8 training sessions improved the knowledge, confidence and attitude of community health workers in counseling of which knowledge was sustained over three months(28). In United Kingdom, a study utilized three days training and 4 weeks' supervision on communication skill in clinical settings, the competence of nurses improved in all the key areas; simulated interview, disclosure of cues and response to cues (26). A study in Mississippi implemented a complex intervention of community health houses in addressing the control of cardio vascular diseases using a one-month certified training and 1year supervision among Community Health Workers (CHWs). Interventions led to a reduction of hospitalization, emergency visits and health care costs reduced (29).

Supervision that followed training in our study had significant effect on the skill of health workers to deliver health education on maternal depression. This is in agreement with earlier recommendations to follow-up a one-day training with supervision (30). In our study, the supervisor's observation showed that motivation to provide maternal depression inclusive health education was better in the supervised clinics more than the un-supervised clinics. In agreement with these findings is that of Heaven et al, study that utilized 4 weeks of supervision following a three- days training. Only the nurses who were supervised improved in the use of open ended questioning, negotiation and psychological exploration. Contrary to our findings, a study conducted on the quality of care of pregnant women and sick children in 7 LMICs showed no effect of supervision but when training and supervision were combined, there was an improved quality of care in Kenya, Namibia, Malawi, Senegal, Tanzania, Uganda and Rwanda (31). Also in Guatemala, Mexico and South Africa, the scaling up of the work of trained CHWs in non-invasive cardiovascular testing was very challenging because there was no structured supervision and the political will (32). lack of motivation of staff to work and work satisfaction was attributed to lack of structured supervision in Tanzania among health workers (33); In Afghanistan, regular training without supervision improved the clinical skill of the PHC workers in the integrated management of childhood illnesses but lack of sustenance of performance of health workers was identified (34). A study in India reported loss in competence within three months after training, because of the training was not followed by supervision(35). In Guinea-Bissau, CHW's compliance with treatment guideline failed because of lack of supervision (36). Ultimately, training and supervision should be implemented together to improve and sustain the quality of services received by health care clients (34);(37);(17); (38). Only one study was found with the compilation of trainings without supervision and the outcome over years has been very effective in the use of mental health first aid. Mental health first aid trainings is a training for the public to promote mental health, it has been proven from 2001-2005 to improve knowledge and attitude in United State America (39) 
Maternal child health clients were the end beneficiaries of the training and supervision interventions. Our study achieved transfer of knowledge of maternal depression from health workers to clients as demonstrated earlier applying the apprentice model (40). This was achieved by researchers monitoring supervisors and supervisors providing supportive supervision to trained health workers. This improvement in knowledge was further demonstrated by the increase in number of those who sought help to their perceived depressive symptoms. The knowledge of these clients improved on the definition of maternal depression, risk factors and consequences in pregnancy and after birth, coping/ prevention, and help seeking. The outcome was contrary to poor knowledge of maternal depression expressed in form of misconceptions (for example maternal depression is ogbanje/ emere (spirit group membership) in a qualitative study which was earlier carried out among maternal child health clients in the community (9). We provided a culturally adapted health talk content with the use of educational materials on maternal depression which was locally developed to address the identified misconceptions in preliminary study (9); (1). Providing health education targeting local beliefs (41) and local practices (42) are keys to the success of interventions such as ours in this study. The local adaptability of training and supervision are the emphasis in the global mental health system(12).

Our study has strength in showcasing the effect of training and supervision on the health workers and maternal-child health service users. Locally developed educational materials on maternal depression were used along with the training and the implementation of the health talk delivery. Although this study was not a randomized control, it employed experimental study design in the real world setting.

Limitation of this study shows up in the incomparable sociodemographic factors in the experimental arm and control arm. The groups were not similar in the educational qualification, years of experience and previous exposure to training on maternal depression. However, this was taken care of by controlling for all these covariates in multivariate analysis. Being a quasi-experimental study, these differences were unavoidable at the design stage.

\section{Conclusions}

Training improved health workers' capacity to communicate maternal depression health education in culturally appropriate way. The follow-up supervision strengthened the skill and the improved the quality of delivering the health education. Hence, maternal-child health clients received quality mental health inclusive health education. Their knowledge improved and they sought help as needed. This implementation can be leveraged to improve maternal mental health service uptake.

\section{Abbreviations}

LMIC: Low and middle income countries

PHC: Primary Health Care

RA: Research Assistants 
CNO/PNO/ CHO: Chief Nursing Officer/Principal Nursing Officer/ Chief Health Officer

CHW: Community Health Worker

LMIC: Low and Middle Income Countries

LGA: Local Government Areas

IBN: Ibadan North, IBNE: Ibadan North East, IBNW: Ibadan North West, IBNW: Ibadan North West, IBSE: Ibadan South East, IBSW: Ibadan South West

GKG: Good Knowledge Gain, GSG: Good Skill Gain; GSEG: Good Self Efficacy Gain

RR: Relative Risk

\section{Declarations}

Ethical approval and consent to participate: Ethical approval was obtained from the Oyo state ethical review board, Nigeria. Reference no AD 13/479/2016. All the health workers and maternal child health clients who participated in this study gave their consent to participate without coercion and they declined when they had to.

Consent for publication: All the authors consented to the publication of this manuscript.

Availability of data and materials: The data generated and analyzed in this study are available and submitted as additional supporting files.

Competing interest: All authors declared that no conflict of interest is attached to this study.

Funding: "This research was supported by the Consortium for Advanced Research Training in Africa (CARTA). CARTA is jointly led by the African Population and Health Research Center and the University of the Witwatersrand and funded by the Carnegie Corporation of New York (Grant No-B 8606.R02), Sida (Grant No:54100113), the DELTAS Africa Initiative (Grant No: 107768/Z/15/Z) and Deutscher Akademischer Austauschdienst (DAAD). The DELTAS Africa Initiative is an independent funding scheme of the African Academy of Sciences (AAS)'s Alliance for Accelerating Excellence in Science in Africa (AESA) and supported by the New Partnership for Africa's Development Planning and Coordinating Agency (NEPAD Agency) with funding from the Wellcome Trust (UK) and the UK government. The statements made and views expressed are solely the responsibility of the Fellow".

Authors' contribution A.O and G jointly drafted the paper, revised the analysis, and revised the manuscript. $O . S$ and $O$ designed the methodology and supervised the implementation. All authors read and reviewed the manuscript. 
Author's information: Adeyinka Adefolarin is the corresponding author. e-mail address correspondence. aadefolarin@cartafrica.org; yinkuss08@gmail.com

Acknowledgement: We acknowledge the contributions of all the staff of the Primary health care and their maternal-child health clients in the Ibadan metropolis, Oyo state, Nigeria.

\section{References}

1. Shidhaye P. Maternal depression: A hidden burden in developing countries. Ann Med Health Sci Res. 2014;4(4):463.

2. Gelaye B, Rondon M, Araya R, Williams MA, Author C. Epidemiology of maternal depression, risk factors, and child outcomes in low-income and middle-income countries HHS Public Access. Lancet Psychiatry. 2016;3(10):973-82.

3. Friedrich MJ. Depression Is the Leading Cause of Disability Around the World. JAMA [Internet]. 2017 Apr 18 [cited 2020 May 12];317(15):1517. Available from: http://jama.jamanetwork.com/article.aspx?doi=10.1001/jama.2017.3826

4. Nillni YI, Mehralizade A, Mayer L, Milanovic S. Treatment of depression, anxiety, and trauma-related disorders during the perinatal period: A systematic review. Clin Psychol Rev. 2018;66:136-48.

5. Posmontier B, Horowitz JA. Postpartum Practices and Depression Prevalences: Technocentric and Ethnokinship Cultural Perspectives. J Transcult Nurs [Internet]. 2004 Jan 29 [cited 2020 Mar 27];15(1):34-43. Available from: http://journals.sagepub.com/doi/10.1177/1043659603260032

6. Stern G, Kruckman L. Multi-disciplinary perspectives on post-partum depression: An anthropological critique. Soc Sci Med. 1983 Jan 1;17(15):1027-41.

7. Maldonado-Duran JM, Fonagy P, Helmig L, Millhuff C, Moody C, Rosen L, et al. In-depth mental health evaluation of a community sample of nonreferred infants with feeding difficulties. Int J Eat Disord [Internet]. 2008 Sep [cited 2020 May 12];41(6):513-9. Available from:

http://www.ncbi.nlm.nih.gov/pubmed/18433018

8. Fisher J, Mello MC de, Patel V, Rahman A, Tran T, Holton S, et al. Prevalence and determinants of common perinatal mental disorders in women in low-and lower-middle-income countries: a systematic review. Bull World Health Organ. 2012;90:139-49.

9. Adefolarin AO, Arulogun OS. Perception of mothers and selected informal maternity caregivers regarding maternal depression in two communities of Ibadan in Nigeria. Arch basic Appl Med. 2018;6(1):17.

10. Atri A, Sharma M. Psychoeducation. Californian J Health Promot. 2007;5(4):32-9.

11. Adefolarin AO, Arulogun OS. Need Assessment for Health Education Service Provision on Maternal Depression Among Primary Health Care Service Providers. Arch basic Appl Med. 2018;6(1):27.

12. Kohrt BA, Bhardwaj A. Training and supervision. In: Global Mental Health and Psychotherapy. Elsevier; 2019. p. 47-65. 
13. Adeyemo DO. Local Government and Health Care Delivery in Nigeria: A Case Study. J Hum Ecol. 2005;18(2):149-60.

14. Rogers N. Minimum Standards for Reception. Eur J Migr Law. 2002;4(2):215-30.

15. Murray LK, Dorsey S, Bolton P, Jordans MJD, Rahman A, Bass J, et al. Building capacity in mental health interventions in low resource countries: An apprenticeship model for training local providers. Int J Ment Health Syst [Internet]. 2011 Nov 18 [cited 2020 Apr 21];5(1):30. Available from: http://ijmhs.biomedcentral.com/articles/10.1186/1752-4458-5-30

16. World Health Organization. Guidelines for Implementing Supportive Supervision. A stepby-step guide with tools to support immunization. World Heal Organ Publ. 2003;

17. Peters DH, Tran NT, Adam T. Implementation research in health: a practical guide. World Health Organization; 2013.

18. Strecher VJ, Rosenstock IM. The health belief model. Cambridge Handb Psychol Heal Med. 1997;113:117.

19. Cochran WG. Planning and analysis of observational studies. Vol. 232. John Wiley \& Sons; 2009.

20. Gabriel A, Violato C. Psychoeducational methods for patients suffering from depression: The knowledge seeking instrument (KSI). J Affect Disord. 2011 Oct;133(3):406-12.

21. Schwarzer R, Hallum S. Perceived teacher self-efficacy as a predictor of job stress and burnout: Mediation analyses. Appl Psychol. 2008 Jul;57(SUPPL. 1):152-71.

22. Bloom BS. Taxonomy of educational objectives. Vol. 1: Cognitive domain. New York McKay. 1956;20:24.

23. Barros AJD, Hirakata VN. Alternatives for logistic regression in cross-sectional studies: An empirical comparison of models that directly estimate the prevalence ratio. BMC Med Res Methodol. 2003;3:1-13.

24. Coutinho LMS, Scazufca M, Menezes PR. Methods for estimating prevalence ratios in crosssectional studies. Rev Saude Publica [Internet]. 2008;42(6):992-8. Available from: http://www.ncbi.nlm.nih.gov/pubmed/19009156

25. Legere LE, Wallace K, Bowen A, McQueen K, Montgomery P, Evans M. Approaches to health-care provider education and professional development in perinatal depression: A systematic review. BMC Pregnancy Childbirth. 2017;17(1).

26. Heaven C, Clegg J, Maguire P. Transfer of communication skills training from workshop to workplace: The impact of clinical supervision. Patient Educ Couns. 2006;60(3):313-25.

27. Selim N. Cultural Dimensions of Depression in Bangladesh: A Qualitative Study in Two Villages of Matlab. J Heal Popul Nutr. 2010;28(1):95-106.

28. Sibeko G, Milligan PD, Roelofse M, Molefe L, Jonker D, Ipser J, et al. Piloting a mental health training programme for community health workers in South Africa: an exploration of changes in knowledge, confidence and attitudes. BMC Psychiatry. 2018;18(1):191. 
29. Kumar M, Mawson A, Lavigine DA, Dove C. Effectiveness of community health workers in healthcare delivery: evidence from the field. J Health Dispar Res Pract. 2018;11(2):5.

30. Fixsen DL, Naoom SF, Blase KA, Friedman RM, Wallace F, Burns B, et al. Implementation research: A synthesis of the literature. 2005;

31. Leslie HH, Gage A, Nsona H, Hirschhorn LR, Kruk ME. Training And Supervision Did Not Meaningfully Improve Quality Of Care For Pregnant Women Or Sick Children In Sub-Saharan Africa. Health Aff [Internet]. 2016 Sep 2 [cited 2020 May 7];35(9):1716-24. Available from:

http://www.healthaffairs.org/doi/10.1377/hlthaff.2016.0261

32. Abrahams-Gessel S, Denman CA, Montano CM, Gaziano TA, Levitt N, Rivera-Andrade A, et al. Lessons from training and supervision of community health workers conducting non-invasive, populationbased screening for cardiovascular disease in four communities in low and middle-income settings: Implications for scaling up. Glob Heart. 2015;10(1):39.

33. Manongi RN, Marchant TC, Bygbjerg IC. Improving motivation among primary health care workers in Tanzania: A health worker perspective. Hum Resour Health. 2006;4:1-7.

34. Tawfiq E, Alawi SAS, Natiq K. Effects of training health workers in integrated management of childhood illness on quality of care for under-5 children in primary healthcare facilities in Afghanistan. Int J Heal Policy Manag. 2020 Jan 1;9(1):17-26.

35. Armstrong G, Kermode M, Raja S, Suja S, Chandra P, Jorm AF. A mental health training program for community health workers in India: Impact on knowledge and attitudes. Int J Ment Health Syst. 2011 Aug 5;5.

36. Lopes SC, Cabral AJ, de Sousa B. Community health workers: To train or to restrain? A longitudinal survey to assess the impact of training community health workers in the Bolama Region, GuineaBissau. Hum Resour Health. 2014;12(1):1-9.

37. Lehmann U, Sanders D. Community health workers: what do we know about them. state Evid Program Act costs impact Heal outcomes using community Heal Work Geneva World Heal Organ. 2007;1-42.

38. Patel V, Weiss HA, Chowdhary N, Naik S, Pednekar S, Chatterjee S, et al. Lay health worker led intervention for depressive and anxiety disorders in India: Impact on clinical and disability outcomes over 12 months. Br J Psychiatry. 2011 Dec;199(6):459-66.

39. Kitchener BA, Jorm AF. Mental health first aid training: review of evaluation studies. Aust New Zeal $\mathrm{J}$ Psychiatry. 2006;40(1):6-8.

40. Murray LK, Dorsey S, Bolton P, Jordans MJD, Rahman A, Bass J, et al. Building capacity in mental health interventions in low resource countries: An apprenticeship model for training local providers. Int J Ment Health Syst [Internet]. 2011 Nov 18 [cited 2020 May 12];5(1):30. Available from: http://ijmhs.biomedcentral.com/articles/10.1186/1752-4458-5-30

41. Topley M. Patients and Healers in the Context of Culture: An Exploration of the Borderland between Anthropology, Medicine, and Psychiatry. By Arthur Kleinman. Berkeley: University of California Press (Comparative Studies of Health Systems and Medical Care, No. 3), 1980. xvi, 427 pp. 
42. Brieger WR, Ramakrishna J, Chirwa BU, Arday-Kotei M. Developing health education for oral rehydration therapy at a rural Nigerian Clinic: Part I. Patient Educ Couns [Internet]. 1988 Jun [cited 2020 Mar 18];11(3):189-202. Available from:

https://linkinghub.elsevier.com/retrieve/pii/0738399188900195

\section{Figures}

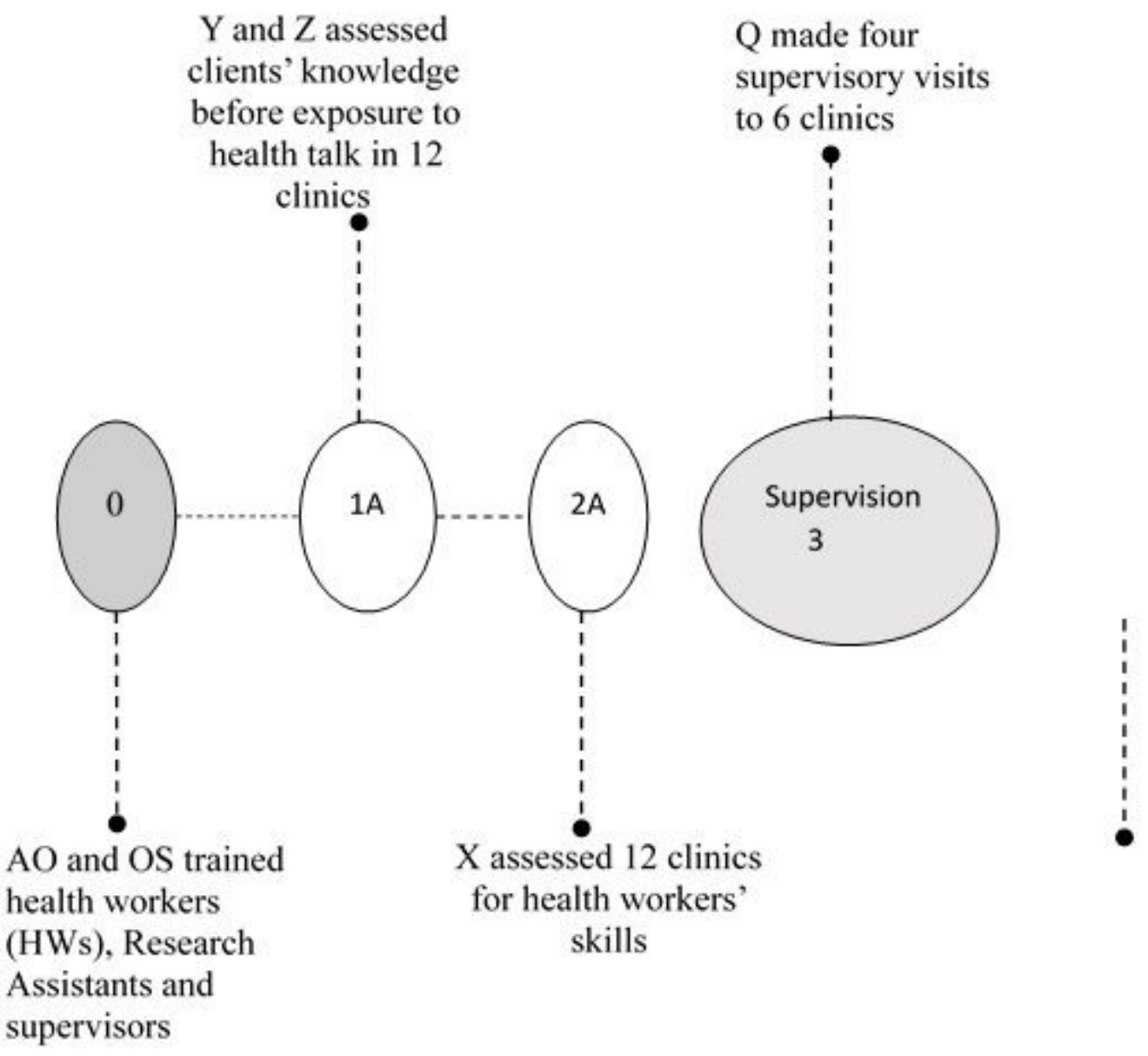

\section{Figure 1}

Data collection on supervision intervention. 


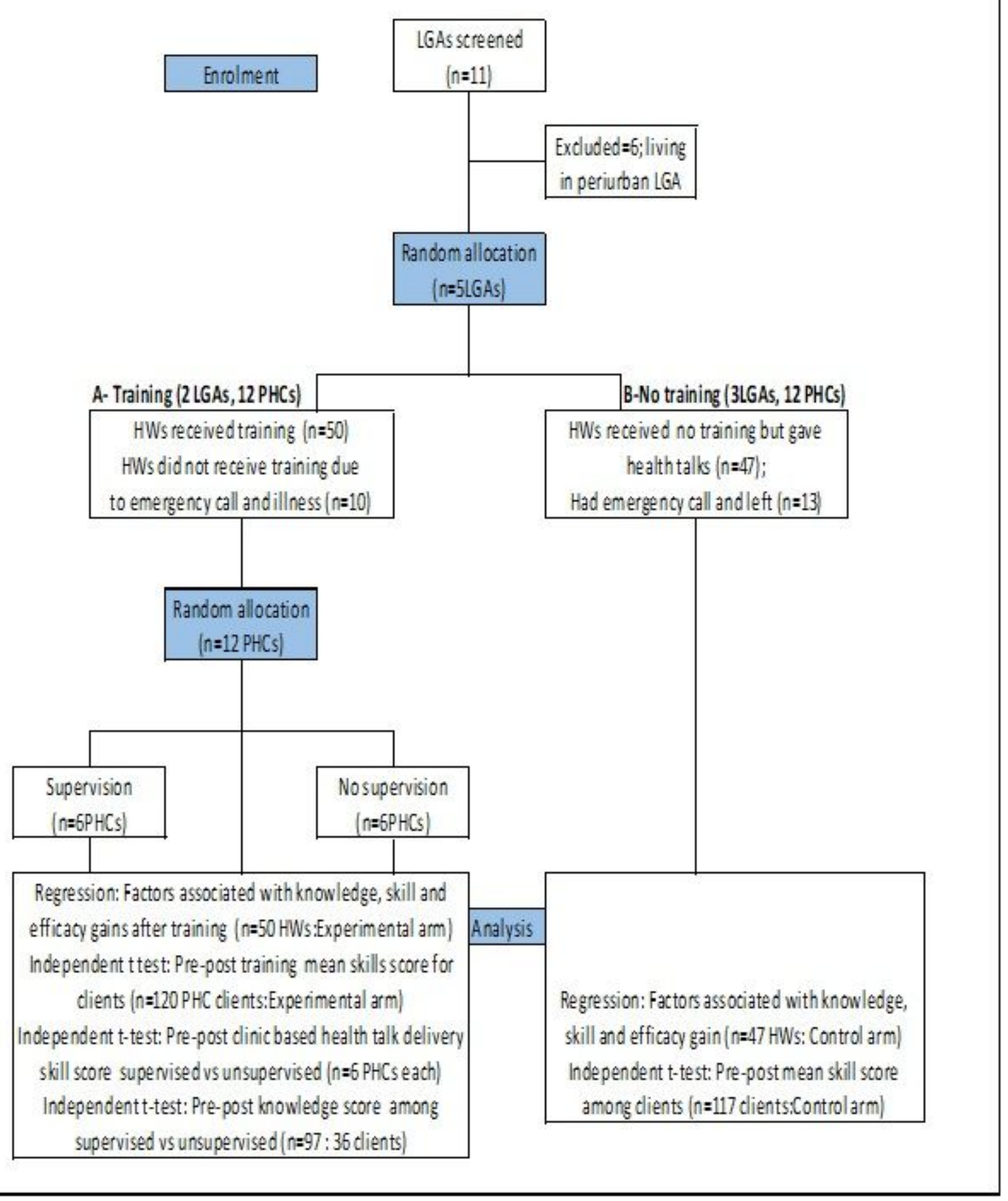

\section{Figure 2}

Participant recruitment, randomization and follow up. 
- EXPERIMENTAL

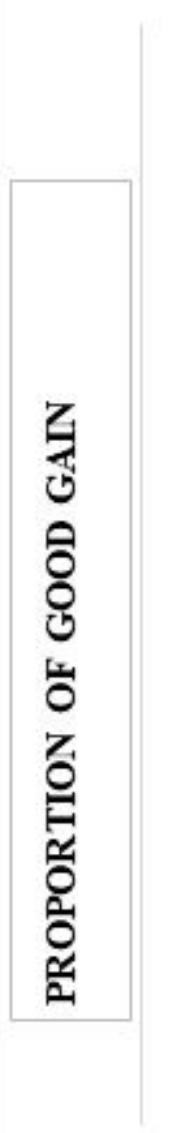

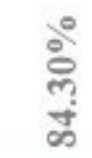
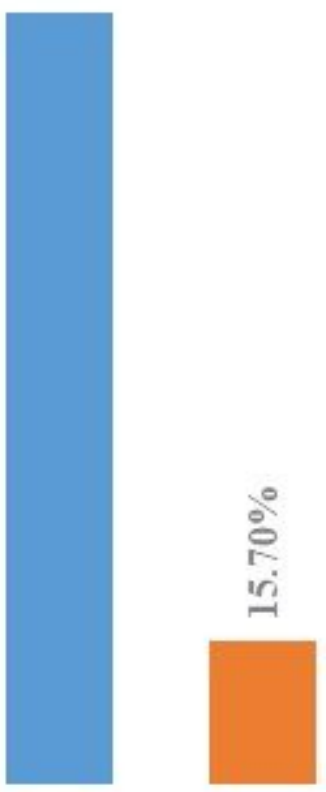

GOOD KNOWLEDGE GAINED
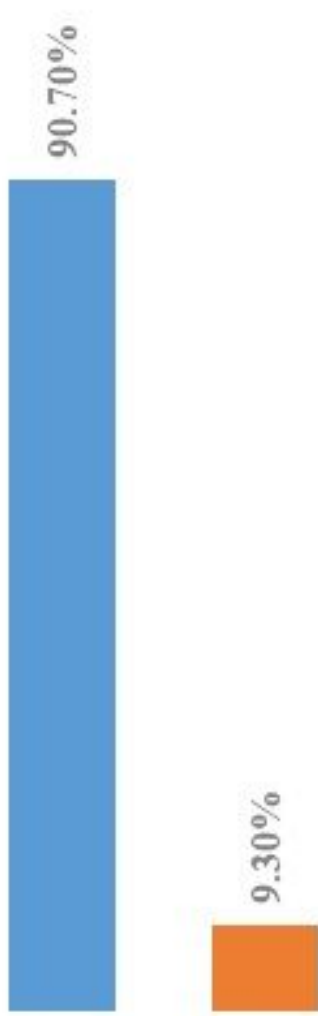

GOOD SKILL GAINED
- CONTROL

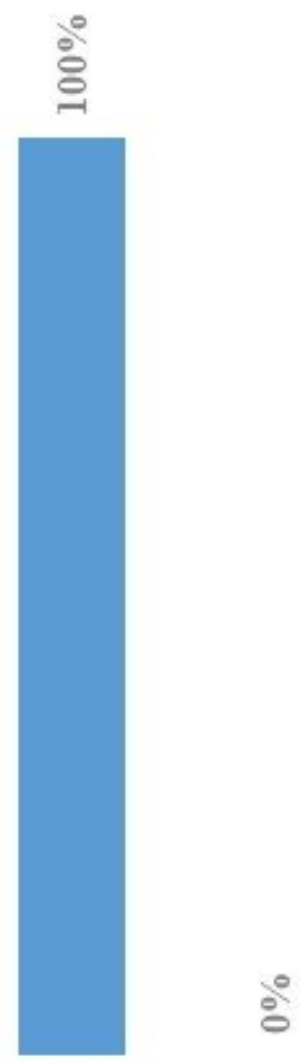

GOOD SELF EFFICACY GAINED

Figure 3

Comparison of knowledge, skills and self-efficacy gains in experimental and control groups.

\section{Supplementary Files}

This is a list of supplementary files associated with this preprint. Click to download.

- INSTRUMENTFORDATACOLLECTIONFORtrainingandsupervision.docx

- SupplementaryTables.pdf 